\title{
PENGARUH MODEL PEMBELAJARAN PROBLEM BASED LEARNING TERHADAP PEMAHAMAN KONSEP IPA SISWA DI SMPN 17 TEBO
}

\author{
M. Junaid ${ }^{1}$, Salahuddin ${ }^{2}$, Rita Anggraini ${ }^{3}$ \\ 1,2 Tadris Fisika UIN Sultan Thaha Saifuddin Jambi, Indonesia \\ Corresponding author email: ritaanggraini510@gmail.com
}

Submit: 15 Maret 2021

Accepted: 22 April 2021

Publish: 30 April 2021

\begin{abstract}
Abstrak
Tujuan dari penelitian ini adalah untuk mengetahui pengaruh problem based learning terhadap pemahaman konsep IPA siswa kelas VII SMPN 17 Tebo tahun ajaran 2020/2021. Populasi penelitian yaitu seluruh siswa kelas VII SMPN 17 Tebo. Pengambilan sampel dilakukan dengan tekhnik cluster random samping. Sampel yang digunakan adalah kelas VII/1 sebagai kelas eksperimen dan kelas VII/2 sebagai kelas kontrol. Variabel terikat dalam penelitian ini adalah pemahaman konsep siswa pada materi perpindahan kalor. Desain eksperimen menggunakan posttest control group design. Instrumen penelitian menggunakan tes pemahaman konspe bentuk multiple choice. Uji hipotesis dilakukan menggunakan uji t pada taraf signifikansi 5\%. Hasil penelitian diperoleh $t_{\text {hitung }}=48.3>$ $t_{\text {tabel }}=1.68$, maka $H_{a}$ diterima. Hal ini menunjukkan ada pengaruh yang signifikan penerapan problem based learning terhadap pemahaman konsep fisika siswa kelas VII SMPN 17 Kabupaten Tebo.
\end{abstract}

Kata Kunci : Problem based learning, pemahaman konsep

\begin{abstract}
The purpose of this study was to determine the effect of problem based learning on student's conceptual understanding of VII class in the $17^{\text {th }}$ State Junior High School of Tebo Regency in the academic year of 2020/2021. The study population was all VII class in the $17^{\text {th }}$ State Junior High School of Tebo Regency. Sampling was done by using side random cluster technique. The sample used was class VII/I as the experimental class and class VII/2 as the control class. The dependent variable in this study is students' understanding of the concept of heat transfer material. The experimental design used the posttest control group design. The research instrument used a test of conceptual understanding of multiple choice format. Hypothesis testing was carried out using the $t$ test at the 5\% significance level. The results showed that $t$ count $=48.3>t$ table $=1.68$, then $H_{a}$ is accepted. This shows that there is a significant effect of the application of problem based learning on the student's conceptual understanding of science on VII class $17^{\text {th }}$ State Junior High School of Tebo Regency.
\end{abstract}

Keywords: Learning model problem based learning, conceptual understanding 


\section{Physics and Science Education Journal (PSEJ) \\ Volume 1 Nomor 1, April 2021}

\section{Pendahuluan}

Fisika merupakan salah satu bagian dari ilmu pengetahuan alam (IPA) atau sains yang memegang peran penting bagi perkembangan kemajuan teknologi suatu bangsa. Fisika merupakan ilmu yang mempelajari gejala, peristiwa atau Fenomena alam, serta mengungkapkan segala rahasia dan hukum semesta. Fisika dipandang penting untuk diajarkan sebagai mata pelajaran karena fisika merupakan wadah menumbuhkan kemampuan berfikir siswa yang berguna untuk memecahkan masalah dalam kehidupan sehari-hari dan membekali peserta didik dengan pengetahuan.

Pemahaman dan sejumlah kemampuan yang merupakan syarat untuk memasuki jenjang pendidikan yang lebih tinggi. Selain itu, fisika adalah pengetahuan fisis, maka untuk mempelajari fisika dan membentuk pengetahuan tentang fisika, diperlukan kontak langsung dengan hal yang ingin diketahui, karena fisika merupakan ilmu yang lebih banyak memerlukan pemahaman dari pada hafalan.

Hakikat sains mencakup proses, produk dan sikap (Hikmawati \& Guanda, 2013). Fisika termasuk salah satu cabang dari IPA, merupakan ilmu yang lahir dan berkembang lewat langkah-langkah observasi, perumusan masalah, penyusunan hipotesis, pengujian hipotesis melalui eksperimen, penarikan kesimpulan, serta penemuan teori dan konsep.

Berdasarkan uraian diatas dapat diketahui bahwa tujuan pembelajaran fisika level SMP/MTS adalah agar peserta didik dapat memahami, mengembangkan observasi dan melaksanakan eksperimen yang berhubungan dengan gejala-gejala yang melibatkan perpindahan panas (kalor), sehingga menumbuhkan kesadaran dan pemahaman terhadap kebesaran Allah SWT penguasa alam semesta. Oleh karena itu, pada pembelajaran sains, khususnya pada materi fisika salah satu tujuan belajar yang hendaknya dicapai adalah pemahaman konsep siswa terhadap materi-materi fisika.

Pemahaman merupakan salah satu aspek pada ranah kognitif. Bloom (dalam Irmayanti, 2012) menyatakan bahwa pemahaman yaitu ketika peserta didik dihadapkan pada suatu komunikasi dan dapat menggunakan ide yang terkandung didalamnya. Komunikasi yang dimaksud dapat dalam bentuk lisan atau tulisan dalam bentuk verbal atau simbolik. Pemahaman memerlukan kemampuan menangkap makna dan arti dari suatu konsep (Sudjana,2013).

Pemahaman siswa terhadap konsep fisika masih sangat rendah, khususnya di Sekolah Menengah Pertama Negeri 17 Kabupaten Tebo. Berdasarkan hasil observasi yang dilakukan peneliti di Sekolah Menengah Pertama Negeri 17 Kabupaten Tebo tanggal 28 September 2020, peneliti menemukan kurangnya pemahaman konsep fisika pada siswa khususnya pada siswa kelas VII, hal ini dapat dilihat dari hasil kerja salah satu siswa yang mengerjakan tugas.

Rendahnya pemahaman konsep fisika juga dapat disebabkan oleh minat belajar siswa, bahwa banyak siswa yang tumbuh tanpa menyukai pelajaran fisika sama sekali, mereka merasa tidak senang dalam mengerjakan tugas-tugas dan merasa bahwa pelajaran fisika itu sulit, menakutkan dan tidak semua orang dapat mengerjakannya.

Berdasarkan hasil observasi saya dimana gejala yang tanpak pada saat proses belajar mengajar proses pembelajaran adalah kemampuan menganalisis dan menyelesaikan soal rendah, siswa pasif dan cenderung suka mencontoh teman, siswa belum mampu berfikir kritis dan sistematis. Berdasarkan hasil wawancara dengan guru dimana guru memberikan soal yang sedikit berbeda dengan contoh yang diberikan, siswa tidak mampu menyelesaikannya. Hal ini disebabkan siswa belajar dengan mengingat fakta dan kurang memahami materi yang dipelajari.

Tabel 1. Ketuntasan belajar IPA siswa di SMPN 17 Tebo

\begin{tabular}{cccc}
\hline Kelas & Siswa & Tuntas & Tuntas \\
VII A & 20 & 6 & 14 \\
VII B & 21 & 5 & 16 \\
\hline
\end{tabular}

Model pembelajaran problem based learning adalah suatu model untuk mengembangkan keterampilan dalam memecahkan masalah dan berfikir kritis secara ilmiah serta mengembangkan pengetahuan peserta didik untuk aktif dalam membangun pengetahuan secara mandiri maupun kelompok. 


\section{Metode Penelitian}

Penelitian ini merupakan penelitian kuantitatif dengan jenis Quasi Experimental. Desain yang digunakan yaitu Pretest-Posttest Control Group Design (Sugiyono, 2012). Penelitian ini melibatkan dua kelompok yaitu kelas eksperimen dan kelas kontrol. Desain penelitian ditunjukkan pada table 2.

Tabel 2. Nonrandomized Pretest-Posttest Contol Group Design

\begin{tabular}{cccc}
\hline Kelompok Kelas & Tes Awal & Perlakuan $(\mathbf{X})$ & Tes Akhir \\
\hline Eksperimen & $\mathrm{O}_{1}$ & $\mathrm{X}$ & $\mathrm{O}_{2}$ \\
Kontrol & $\mathrm{O}_{3}$ & - & $\mathrm{O}_{4}$ \\
\hline
\end{tabular}

Keterangan :

$\mathrm{X} \quad$ : Problem base learning

- $\quad$ : Pembelajaran kovensional

$O_{1} \quad$ : Pretets pemahaman konssep pada kelas eksperimen.

$\mathrm{O}_{2} \quad$ : Posttets pemahaman konssep pada kelas eksperimen.

$\mathrm{O}_{3} \quad$ : Pretets pemahaman konssep pada kelas kontrol

$\mathrm{O}_{4} \quad$ : Posttets pemahaman konssep pada kelas kontrol.

\section{Populasi dan Sampel Penelitian}

Populasi penelitian ini adalah siswa VII SMPN 17 Tebo tahun ajaran 2019/2020 yang terdiri dari dua kelas yaitu kelas VII/1 dan VII/2. Penelitian ini menggunakan total sampling. Pemilihakan kelas eksperimen dan control dilakukan secara acak dan terpilih kelas eksperimen adalah kelas VII/1 dan kelas kontrol adalah kelas VII/2.

\section{Instrumen Penelitian}

Instrumen dalam penelitian ini meliputi lembar observasi keterlaksanaan pembelajaran dan tes pemahaman konsep IPA. Lembar observasi digunakan untuk mengamati jalannya proses pembelajaran. Tes pemahaman konsep IPA diberikan sebelum mengikuti pembelajaran (pretest) dan setelah mengikuti pembelajaran (posttest). Tes pemahaman konsep IPA berupa soal pilihan ganda yang berjumlah 30 soal.

\section{Analisis Data}

Teknik analisis data pada penelitian ini meliputi uji prasyarat hipotesis dan uji hipotesis. Uji prasyarat hipotesis terdiri dari uji normalitas dan uji homogenitas. Uji hipotesis menggunakan menggunakan uji Independent Sample T Test.

\section{Hasil Penelitian dan Pembahasan}

Penelitian ini dilakukan pada dua kelompok yaitu kelas eksperimen dan kelas control. Siswa diberikan prestest sebelum mengikuti pembelajaran untuk mengetahui kemapuan awal siswa. Pada kelas eksperimen, siswa megikuti pembelajaran menggunakan model problem base learning. Pada kelas control, siswa mengikuti pembelajaran biasa (kovensional). Setelah mengikuti pembelajaran, siswa diberi posttest untuk mengetahui pemahaman konsep IPA siswa. Data posttest pemahaman konsep IPA pada kelas eksperimen dan kelas kontrol dapat dilihat pada tabel 3. 
Tabel 3. Hasil posttest kelas eksperimen dan kelas kontrol

\begin{tabular}{ccc}
\hline Rata-rata Hitung & Kelas Eksperimen & Kelas Kontrol \\
\hline Mean & 85.75 & 80.55 \\
Standar Deviasi & 7.98 & 6.34 \\
Maximum & 95 & 95 \\
Minimum & 70 & 65 \\
\hline
\end{tabular}

Berdasarkan hasil posttes diperoleh data rata-rata kelas eksperimen sebesar 85.75 dan kelas control sebesar 80.55. Pada table 1 di atas terlihat rerata pemahaman konsep IPA yang didapat pada kelas eksperimen lebih tinggi dibandingkan dengan kelas kontrol. Untuk mengetahui apakah perbedaan yang signifikan maka perlu dilakukan uji statistic inferensial. Uji hipotesis dilakukan menggunakan uji t.

Berdasarkan hasil uji hopteisis pada taraf signifikansi $5 \%$, dengan df $=39$ diperoleh $t_{\text {tabel }}=$ $t_{\text {hitung }}>t_{\text {tabel }}$ atau $48.3>1.68$, maka $\mathrm{H}_{0}$ ditolak. Hal ini menunjukkan bahwa pemahaman konsep IPA siswa yang menggunakan model problem based learning lebih baik dari hasil belajar siswa IPA yang menggunakan pembelajaran konvensional. Besarnya Effect Size yang di peroleh yaitu d =0,72. Model problem based learning memberikan pengaruh signifikan terhadap pemahaman konsep IPA siswa pada materi perpindahan kalor di kelas VII SMPN 17 Tebo.

Perbedaan skor rata-rata tersebut tidak terjadi secara kebetulan, melainkan terjadi karena adanya perbedaan perlakuan yang diberikan kepada kelas eksperimen dan kelas kontrol. Perbedaan hasil posttes kelas eksperimen dan kelas kontrol tersebut menunjukkan bahwa pemahaman konsep fisika siswa yang melaksanakan pembelajaran dengan strategi pembelajaran problem based learning (PBL) lebih tinggi daripada pemahaman konsep fisika siswa yang menggunakan pembelajaran ceramah (konvensional).

Strategi pembelajaran problem based learning (PBL) merupakan salah satu strategi pembelajaran yang berpusat pada siswa, yang menuntut siswa untuk berpikir lebih kritis dan terampil dalam memecahkan masalah, dan memperoleh pengetahuan. Kegiatan pembelajaran di kelas eksperimen diawali dengan pemberian motivasi, penyampaian tujuan pembelajaran dan pemberian apersepsi. Apersepsi adalah mengulang materi pelajaran sebelumnya yang sudah diajarkan, agar setiap siswa mengingat kembali apaapa yang sudah diajarkan (Muhammad Maksum, 2014, hlm.79). Sehingga siswa dapat membangun dasar yang kuat sebelum melangkah ke tahap selanjutnya.

Kegiatan inti pembelajaran dimulai dengan guru mengajak siswa untuk mengamati tentang perpindahan kalor, membuktikan bahwa partikel dapat bergerak, dan guru membimbing peserta didik dalam pembentukan kelompok yang terdiri 4-5 orang setiap kelompok, memfasilitasi peserta didik melakukan percobaan di laboraturium, kemudian memeriksa kegiatan eksperimen yang dilakukan oleh peserta didik apakah sudah dilakukan dengan benar atau belum. Jika masih ada peserta didik atau kelompok yang belum dapat melakukan dengan benar, guru dapat langsung memberikan bimbingan.

Kegiatan akhir pembelajaran guru bersama siswa meluruskan kesalahan pemahaman dan memberikan penguatan. Selanjutnya siswa dibimbing oleh guru untuk menyimpulkan materi yang telah dipelajari. Pada kegiatan akhir guru memberikan PR untuk siswa berlatih di rumah dan juga memberikan pujian dan penghargaan kepada siswa yang memperoleh nilai yang bagus, sehingga siswa merasa dihargai dan bangga akan hasil yang dicapainya.

Pembelajaran konvesional pada kelas kontrol. Pada awal pembelajaran guru menyampaikan tujuan pembelajaran dan apersepsi. Saat proses pembelajaran guru menjelaskan materi dengan ceramah. Guru memberikan kesempatan kepada siswa untuk bertanya jika ada materi yang kurang jelas. Guru meminta siswa untuk mengerjakan soal-soal latihan di buku paket sekolah untuk memperlancar dan memahami apa yang baru saja dipelajari. Guru memberikan kesempatan kepada siswa untuk bertanya mengenai pembahasan latihan yang kurang dimengerti. Selanjutnya hasil pekerjaannya dikumpulkan kepada guru 


\section{Physics and Science Education Journal (PSEJ) \\ Volume 1 Nomor 1, April 2021}

untuk memberikan penilaian. Dapat diamati ketika ada bagian yang tidak dimengerti hanya beberapa orang saja yang aktif untuk bertanya di karenakan pembelajaran yang kurang menarik.

Hal ini membuktikan bahwa kelas eksperimen lebih baik dibandingkan kelas kontrol. Pada kelas eksperimen siswa lebih aktif, ketika guru menjelaskan siswa terlibat aktif didalamnya, memperhatikan dan bertanya apabila ada yang tidak mengerti. Dalam pembagian tugas dan kelompok mereka antusias dan semangat mengerjakan tugas yang diberikan oleh guru, mereka saling bertukar pikiran untuk mengeluarkan ide-ide atau pendapatnya sesama anggota kelompok. Sedangkan pada pembelajaran kelas kontrol siswa kurang terlibat aktif di dalamnya, diamati ketika ada bagian yang tidak dimengerti hanya beberapa siswa saja yang aktif untuk bertanya, siswa lebih banyak diam, menerima apa adanya yang dijelaskan, dan tidak berkomentar. Ketika mengerjakan soal yang ada pada LDS berbeda dengan contoh yang diberikan, siswa kesulitan untuk menyelesaikan, mereka tidak mau bertanya justru mengobrol dengan temannya dan tidak bersemangat untuk menyelesaikan soal yang diberikan.

Berdasarkan proses pembelajaran dengan menggunakan strategi pembelajaran problem based learning yang telah dipaparkan lebih efektif karena diperoleh skor tes siswa yang lebih baik dari pada siswa yang menggunakan pembelajaran konvensional. Meskipun disini sudah terbukti bahwa strategi pembelajaran problem based learning sudah sangat tepat diterapkan, maka akan tetapi masih ada beberapa siswa yang masih mendapatkan pemahaman konsep fisika yang rendah. Hal ini disebabkan beberapa faktor diantaranya adalah adanya kemampuan siswa dalam menangkap pelajaran masih kurang, masih ada sebagian siswa yang kurang konsentrasi dalam pembelajaran berlangsung, masih ada yang ribut, dan masih ada yang bermalas-malasan dalam belajar sehingga pemahaman konsep fisika yang mereka dapat tidak memuaskan.

Model pembelajaran berbasis masalah (Problem Based Learning) adalah salah satu model pembelajaran inovatif yang memberikan kondisi belajar aktif kepada peserta didik, pengertian strategi berbasis masalah adalah suatu strategi pembelajaran yang melibatkan peserta didik untuk memecahkan suatu masalah melalui tahapan-tahapan metode ilmiah sehingga peserta didik dapat mempelajari pengetahuan yang berhubungan dengan masalah tersebut dan sekaligus memiliki keterampilan untuk memecahkan masalah.

Menurut Dick dan Carey (2009) menjelaskan bahwa strategi pembelajaran terdiri atas seluru komponen materi pembelajaran dan prosedur atau tahapan kegiatan belajar yang akan digunakan oleh guru dalam rangka membantu peserta didik mencapai tujuan pembelajaran tertentu. Dalam pembelajaran sains, penerapan kedua teori tersebut dapat dikembangkan dengan karakteristik terfokus pada tujuan pembelajaran dan materi tertentu. Pembelajaran ditujukan untuk pencapain pengetahuan deklaratif, prosedural, sikap dan keterampilan proses sains termasuk keterampilan komunikasi. Materi dikembangkan berkaitan dengan kurikulum yang berlaku, yang mendorong pengembangan kemampuan problem based learning, berkaitan dengan perkembangan siswa,berorientasi pada falsafah pendidikan yang terkait, kegiatan belajar mengajar (KBM) sains, serta memiliki keterkaitan antara sains, matematika, teknologi dan masyarakat. Selain itu peneliti lain yang relevan yaitu Tandogan dan Orhan (2007) yang bertujuan untuk mengeksplorasi bagaimana pengaruh model problem based learning terhadap prestasi belajar dan penguasaan konsep fisika oleh siswa. Penelitian dengan desain Mixed Methode ini menemukan bahwa penggunaan model Problem Based Learning berpengaruh positif terhadap perkembangan konseptual siswa dan menjaga miskonsepsi siswa yang berada pada level terendah.

\section{Simpulan}

Rerata posttest pemahaman konsep IPA siswa pada materi perpindahan kalor yang menggunakan Problem Based Learning (PBL) sebesar 85.75. Retata posttest pemahaman konsep IPA siswa pada materi perpindahan kalor yang menggunakan pembelajaran konvensional sebesar 80.55. Hasil uji t pada taraf signifikansi $5 \%$ diperoleh $t_{\text {hitung }}=48.3>t_{\text {tabel }}=1.68$ dan hasil uji Effect Size, dapat diperoleh $\mathrm{d}=0,72$. Hal ini menunjukkan bahwa $H_{a}$ diterima, artinya terdapat pengaruh 
yang signifikan penerapan problem based learning terhadap pemahaman konsep IPA siswa kelas VII SMPN 17 Tebo.

\section{Referensi}

Ajeng Suryani, Parsaoran Siahaan, dan Achmad Samsudin. (2015). Pengembangan Instrumen Tes untuk Mengukur Keterampilan Proses Sains Siswa SMP pada Materi Gerak. Prosiding Simposium Nasional Inovasi dan Pembelajaran Sains 2015 (SNIPS 2015) 8 dan 9 Juni 2015, Bandung, Indonesia.

Bekti Wulandari, Pengaruh Problem Based Learning Terhadap Hasil Belajar Ditinjau dari Motovasi Belajar PLC di Smk (Jurnal)

Ikhwani Sofiya, Pengaruh Model Pembelajaran Problem Based Learning (PBL) Terhadap Hasil Belajar Siswa Kelas VII Smp N 1 Hiliran Gumanti Kabupaten Solok tahun pelajaran 2015/2016.

Jennifer A Smift, Pengaruh Pembelajaran Berbasis Masalah (PBL) pada Kesarjanaan Medis Pendidikan Tentang Pendidikan Pasca Sarjana Pascasarjana, (Jurnal Internasional)

M.Taufik Amir, Inovasi Pendidikan Melalui Problem Based Learning, (Jakarta: Prenadamedia Group, 2010)., h. 52.

Sugiyono. (2013). Metode Penelitian Kuantitatif dan Kualitatif dan R\&D. Bandung: Alfabeta.

Tandoga, R. O., \& Orhan, A. (2007). The Effects of Problem Based Learning in Science Education on studen' Academic Achievement, Attitude and Concept Learning. Online Submission, 3(1), 71-81

Trianto. (2012). Model Pembelajaran Terpadu: Konsep, Strategi, dan Implentasinya dalam Kurikulum Tingkat Satuan Pendidikan (KTSP). Bumi Aksara: Jakarta.

Yunin Nurun Nafiah, Penerapan Model Problem Based Learning Untuk Meningkatkan Keterampilan Berfikir Kritis dan Hasil Belajar Siswa, (Jurnal). 